\title{
Monetary Policy Dynamics in the Euro Area
}

\author{
Patrick Fève \\ University of Toulouse (GREMAQ and IDEI) \\ and Banque de France (DGEI-DIR-Service de Recherche en économie et finance) \\ Julien Matheron* \\ Banque de France (DGEI-DIR-Service de Recherche en économie et finance) \\ Céline Poilly \\ Banque de France (DGEI-DIR-Service de Recherche en économie et finance)
}

November 10, 2006

\begin{abstract}
We investigate identification issues in estimated Taylor rules. Embedding two alternative views about monetary policy, inertia versus serially correlated shocks, in a single equation, we show that using euro data, it is impossible to discriminate between these two competing representations.
\end{abstract}

Keywords: Taylor rules, Inertia, Serially Correlated Shocks, Identification.

JEL Codes: C22, E52.

\footnotetext{
*Corresponding author. Banque de France, DGEI-DIR-RECFIN (41-1391), 31 Rue Croix des Petits Champs, 75049 Paris cedex 01, France. Tel: +33 1429229 97, Fax: +33 $14292 \quad 62$ 92. Email: julien.matheron@banque-france.fr. The views expressed herein are those of the authors and do not necessarily reflect those of the Banque de France.
} 


\section{Introduction}

Over the recent years, there has been a renewed interest in modelling monetary policymaking in terms of simple rules. In this literature, the augmented Taylor rule has become the workhorse description of central bank behavior. The view emerging from this rules is that of a sizable policy inertia, either in the US or in the euro zone. ${ }^{1}$ However, following Rudebusch $(2002,2005)$, an alternative interpretation of actual persistence in monetary policy is the presence of serially correlated shocks in the realizations of the interest rate rule. Importantly, this alternative view of monetary policy yields implications that are completely opposite to those of the partial adjustment hypothesis. Under serially correlated shocks, the central bank does not effectively smooth the interest rate, even though the latter might prove persistent.

The purpose of the present paper is to disentangle these two opposite views in the case of the euro area. To do so, we embed both representations in a single equation so as to discriminate between the respective roles of serially correlated shocks and interest rate smoothing. However, single equation models of partial adjustment with serially correlated shocks are subject to well known identification and multiple optima issues (Griliches, 1967, Blinder, 1986, McManus et al. 1994). A robust finding of this literature is that the identification problem may arise more frequently with regressors that are of minor empirical importance. In our case, this problem would appear when the target does not display enough variability.

So as to properly deal with this problem, we adopt a careful estimation procedure which takes into account the potential existence of multiple local optima. This allows us to characterize multiple interest rate rules with dramatically differing implications in terms of target. Our results suggest the presence of a the above-mentioned multiple local optima problem, which makes it very hard to discriminate between the two competing representations about monetary policy in the euro area.

\footnotetext{
${ }^{1}$ See Clarida et al. (2000); Gerlach and Schnabel (2000); Gerlach-Kristan (2003).
} 


\section{Augmented Taylor Rules for the Euro Area}

We investigate whether monetary policy can be adequately approximated by a rule of the form

$$
\begin{gathered}
\bar{\imath}_{t}=\alpha_{0}+\alpha_{\pi} \pi_{t}+\alpha_{y} y_{t}, \\
i_{t}=\rho i_{t-1}+(1-\rho) \bar{\imath}_{t}+\epsilon_{t}, \\
\epsilon_{t}=\lambda \epsilon_{t-1}+\nu_{t}, \quad \nu_{t} \sim \operatorname{iid}\left(0, \sigma_{\nu}^{2}\right),
\end{gathered}
$$

where $\pi_{t}$ is the inflation rate, $y_{t}$ is the output gap, and $i_{t}$ is the nominal interest rate. Equation (1) is similar to that proposed by Taylor (1993). Here $\bar{\imath}_{t}$ is the target interest rate that depends on current inflation and the output gap. The parameters $\alpha_{\pi}$ and $\alpha_{y}$ govern the sensitivity of the desired level of the nominal interest rate to $\pi_{t}$ and $y_{t}$.

The above rule combines two different views about monetary policy. Equation (2) represents a process of interest-rate smoothing by the central bank. The resulting interest rate inertia finds theoretical support: (a) by opting for a gradual policy, monetary authorities can decrease the short-run volatility of the interest rate as well as that of asset prices; (b) partially adjusting the nominal interest rate impacts on private sector expectations, so that forward-looking agents trust that monetary authorities are committed to a gradual policy rule and thus engaged in controlling macroeconomic fluctuations; and (c) widespread model uncertainty can call for cautious actions, which results in inertial monetary policy. ${ }^{2}$

Equation (3) represents an alternative hypothesis to the apparent smoothing of the interest rate and emphasizes the effects of serially correlated policy shocks, $\epsilon_{t}$, in the realizations of the policy rule. These shocks may represent any contingent event the central bank faces when deciding the interest rate, such as credit crunches or financial crises. ${ }^{3}$ Moreover, the use of real-time data could also reinforce the apparent degree of serial correlation in policy shocks. Indeed, the incomplete information used when estimating these parameters is modified by revisions over time, thus affecting the policy rate level in a persistent way. Overall, even though the central bank does not especially

\footnotetext{
${ }^{2}$ See, among others, Goodfriend (1987) and Woodford (2003).

${ }^{3}$ See Taylor (1993) or Rudebusch (2002).
} 
smooth the nominal interest rate, the latter can exhibit a substantial amount of persistence as observed in actual data.

\section{Identification Issues}

Obviously one would like to discriminate between these two competing views about monetary policy. Unfortunately, this is not an easy task because in the process of doing so, a researcher might encounter the well-known problem of identification and multiple optima in the partial adjustment model with serially correlated shocks (see, e.g. Griliches, 1967, Blinder, 1986, McManus et al. 1994).

To see this problem most clearly, let us consider our simple representation of the monetary policy combining partial adjustment and serially correlated shocks

$$
i_{t}=(\rho+\lambda) i_{t-1}-\rho \lambda i_{t-2}+(1-\rho)\left(\bar{\imath}_{t}-\lambda \bar{\imath}_{t-1}\right)+\nu_{t} .
$$

Suppose that $\bar{\imath}_{t}$ is such that $\mathrm{E}\left\{\bar{\imath}_{t}\right\}=\bar{\imath}$ and $\operatorname{Var}\left(\bar{\imath}_{t}\right)=0$, so that the policy function rewrites

$$
i_{t}=(1-\rho)(1-\lambda) \bar{\imath}+(\rho+\lambda) i_{t-1}-\rho \lambda i_{t-2}+\nu_{t} .
$$

In this case, the parameters $\rho$ and $\lambda$ are not separately identified. To see this, consider the reduced form associated to the monetary policy

$$
i_{t}=\beta_{0}+\beta_{1} i_{t-1}+\beta_{2} i_{t-2}+\nu_{t}
$$

Parameters $\rho$ and $\lambda$ are only identified when $\rho=\lambda$. However, this case is inconclusive as it puts the same weights on the two competing representations of the monetary policy. Except for this very special case, there does not exist a unique solution for $\rho$ and $\lambda$ as a function of the reduced form parameters $\beta_{1}$ and $\beta_{2}$. Indeed, provided that $\beta_{2} \neq 0$, the solutions for $\lambda$ and $\rho$ are given by

$$
\lambda=\frac{\beta_{1} \pm \sqrt{\beta_{1}^{2}+4 \beta_{2}}}{2}, \text { and } \rho=\beta_{1}-\lambda,
$$

where $\beta_{1}^{2}+4 \beta_{2}=(\rho-\lambda)^{2} \geq 0$. This means that two sets of values for $\lambda$ and $\rho$ are observationally equivalent. The first solution is $\rho$ large and $\lambda$ small. The second is $\rho$ small and $\lambda$ large. Thus when 
$\bar{\imath}_{t}$ is constant, we cannot distinguish between an inertial monetary policy with transitory shocks and a monetary policy with small partial adjustment and highly serially correlated shocks. When $\bar{\imath}_{t}$ is more volatile, this problem of multiple optima can potentially disappear. ${ }^{4}$ However, nothing guarantees this in practice.

\section{Empirical Results}

We focus on the euro area for the sample period 1987(1)-2004(4), using data from AWM database (Fagan et al., 2005). The short term nominal interest rate is used as a measure of $i_{t}$. Following Gerlach-Kristen (2003), the inflation rate is calculated as a change over four quarters of the HIPC and the output gap $y_{t}$ is defined as the residual of a regression of the logarithm of real GDP on a polynomial in time. Contrary to Gerlach and Schnabel (2000) or Gerlach-Kristen (2003), we do not include dummies capturing the ERM 1992 crisis since such a large shock should in principle be captured by $\nu_{t}$. The equation to be estimated writes

$$
i_{t}=(\rho+\lambda) i_{t-1}-\rho \lambda i_{t-2}+(1-\rho)\left[(1-\lambda) \alpha_{0}+\alpha_{\pi}\left(\pi_{t}-\lambda \pi_{t-1}\right)+\alpha_{y}\left(y_{t}-\lambda y_{t-1}\right)\right]+\nu_{t} .
$$

The parameters $\rho, \lambda, \alpha_{0}, \alpha_{\pi}$, and $\alpha_{y}$ are estimated by Non Linear Least Squares (NLLS). Given that we cannot exclude a priori the presence of multiple local optima, we resort to a fine grid search to initialize the estimation algorithm.

Table 1 reports the estimation results. The first column reports parameter estimates when the estimation algorithm is initialized with a large $\lambda$ and a small $\rho$. The second reports results when we impose the constraint $\rho=0$. The third column reports parameter estimates when the estimation algorithm is initialized with a large $\rho$ and a small $\lambda$. Column four gives the results when we impose $\lambda=0$. Finally, the last column shows results obtained when we impose $\lambda=\rho$.

In addition, figure 1 provides a contour plot of the Sum of Squared Residuals $(S S R)$ obtained for a fine grid of values on $(\lambda, \rho)$. More precisely, at each $(\lambda, \rho)$ node, the parameters $\left(\alpha_{0}, \alpha_{\pi}, \alpha_{y}\right)$ are re-estimated so as to minimize the $S S R$. The estimation results of each column of table 1 are also

\footnotetext{
${ }^{4}$ See McManus et al. (1994).
} 
reported (the pentagram, hexagram, triangle, square, and circle correspond respectively to columns $1,2,3,4$, and 5). The figure displays the $45^{\circ}$ line along which the restriction $\lambda=\rho$ is always true. Finally, the figure also includes a shaded area inside of which the Taylor principle $\left(\alpha_{\pi}>1\right)$ is not enforced. The figure clearly illustrates the presence of the above-mentioned multiple optima problem.

Comparing columns 1 and 3 shows that there are two optima. The first one is obtained for persistent shocks to monetary policy and moderate interest rate inertia. The second is the symmetric. More importantly, the target parameters sharply differ. Under the first configuration (column 1), monetary policy is passive while very aggressive in the second (column 3). Indeed, in column 1, the estimated values of $\alpha_{\pi}$ and $\alpha_{y}$ are rather small and $\alpha_{\pi}$ is not significantly different from 0 . To the contrary, when the policy rule is inertial, this latter is precisely estimated and $\alpha_{\pi}$ and $\alpha_{y}$ both take on large values, close to those obtained by Gerlach-Kristen (2003). A troubling result is that, based on the $S S R$ or the $R^{2}$ of the regression, it is extremely difficult to discriminate between these very opposite views about monetary policy. In addition, the Ljung-Box specification test of omitted serial correlation is equally supportive of both representations. Overall, our findings constitute a further illustration of the lack of identification of the partial adjustment model with serially correlated shocks in finite sample.

As explained above, the case $\lambda=\rho$ is the only instance where the identification problem vanishes. However, this restrictions does not allow us to discriminate between the two competing views about monetary policy. Nevertheless, in this identified case we are able to assess the monetary policy target. Fortunately, we find that the Taylor principle is enforced. This can be verified in figure 1 , where the $45^{\circ}$ line is well above the shaded area. In addition, the parameters are all precisely estimated.

To complement this study, we also investigated the restriction $\lambda=0$ or $\rho=0$ in equation (4). They are both rejected by the Ljung-Box specification test, suggesting that the data favor a scenario with both inertia and serially correlated shocks so as to mimic the interest rate behavior in the euro zone, as argued by Castelnuovo (2006). 


\section{References}

Blinder, A.S., 1986. More on the speed of adjustment in inventory models. Journal of Money, Credit, and Banking, 18, 355-365.

Castelnuovo, E., 2006. Taylor rules and interest rate smoothing in the euro area. Mimeo, University of Padua.

Clarida, R., Galí, J., Gertler, M., 2000. Monetary policy rules and macroeconomic stability: evidence and some theory. Quarterly Journal of Economics, 115, 147-180.

Fagan, G., Henry, J., and Mestre, R., 2005. An area-wide model (AWM) for the euro area. Economic Modelling, 22, 39-59.

Gerlach, S., Schnabel, G., 2000. The Taylor rule and interest rates in the EMU area. Economic Letters, $67,165-171$.

Gerlach-Kristen, P., 2003. Interest rate reaction function and the Taylor rule in the euro area. ECB Working paper 258.

Goodfriend, M., 1987. Interest rate smoothing and price level trend-stationarity. Journal of Monetary Economics, 19, 335-348.

Griliches, Z., 1967. Distributed lags: A survey. Econometrica, 35, 16-49.

McManus, D.A., Nankervis, J.C., Savin, N.E., 1994. Multiple optima and asymptotic approximations in the partial adjustment model. Journal of Econometrics, 62, 91-128.

Rudebusch, G.D., 2002. Term structure evidence on interest rate smoothing and monetary policy inertia. Journal of Monetary Economics, 49, 1161-1187.

Rudebusch, G.D., 2005. Monetary policy inertia: Fact or fiction? Federal Reserve Bank of San Francisco, Working paper 205-19.

Taylor, J.B., 1993. Discretion versus policy rules in practice. Carnegie-Rochester Conference Series on Public Policy, 39, 195-214. 
Woodford, M., 2003. Interest and Prices: Foundation of a Theory of Monetary Policy. Princeton University Press, Princeton. 


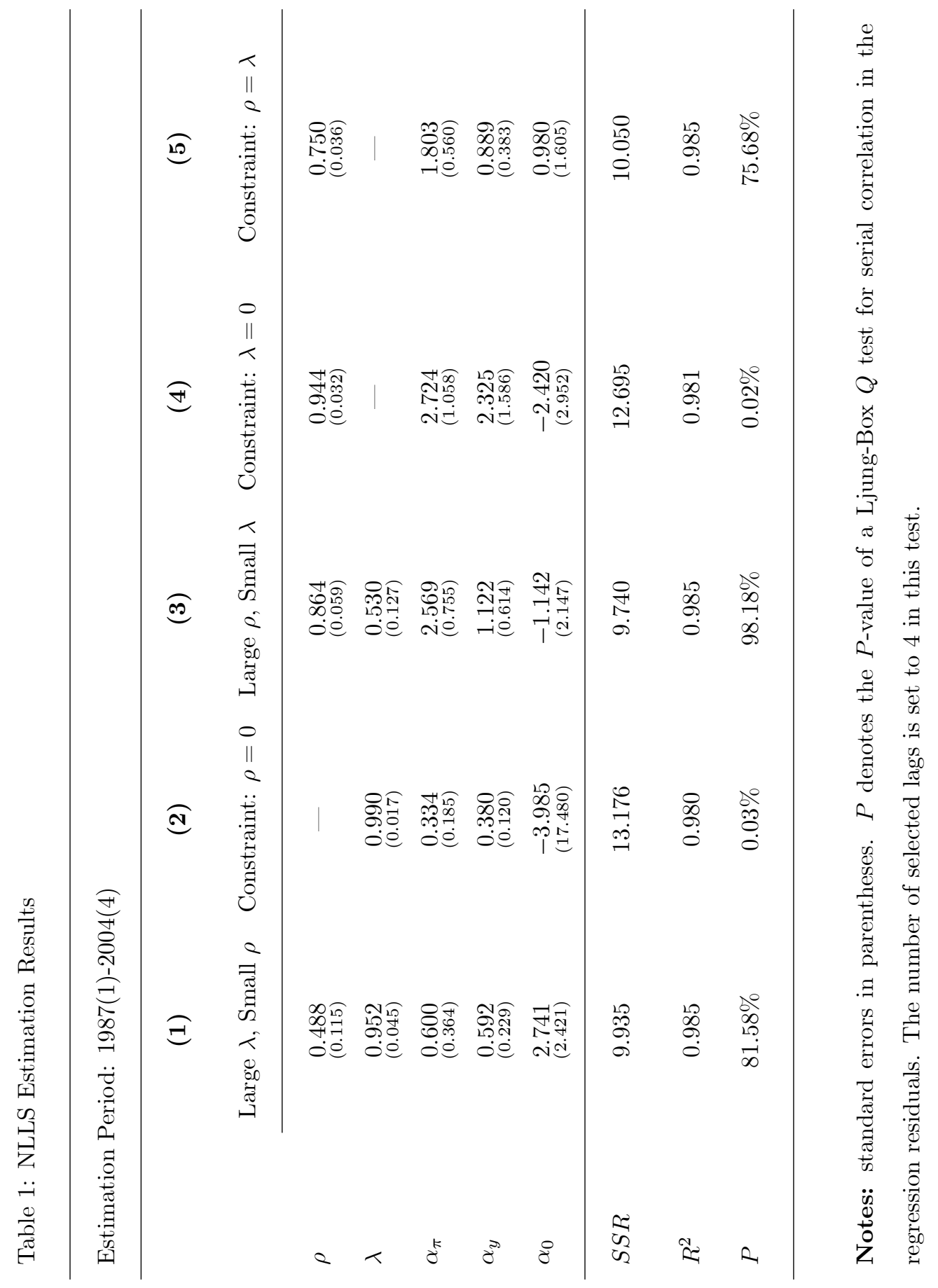




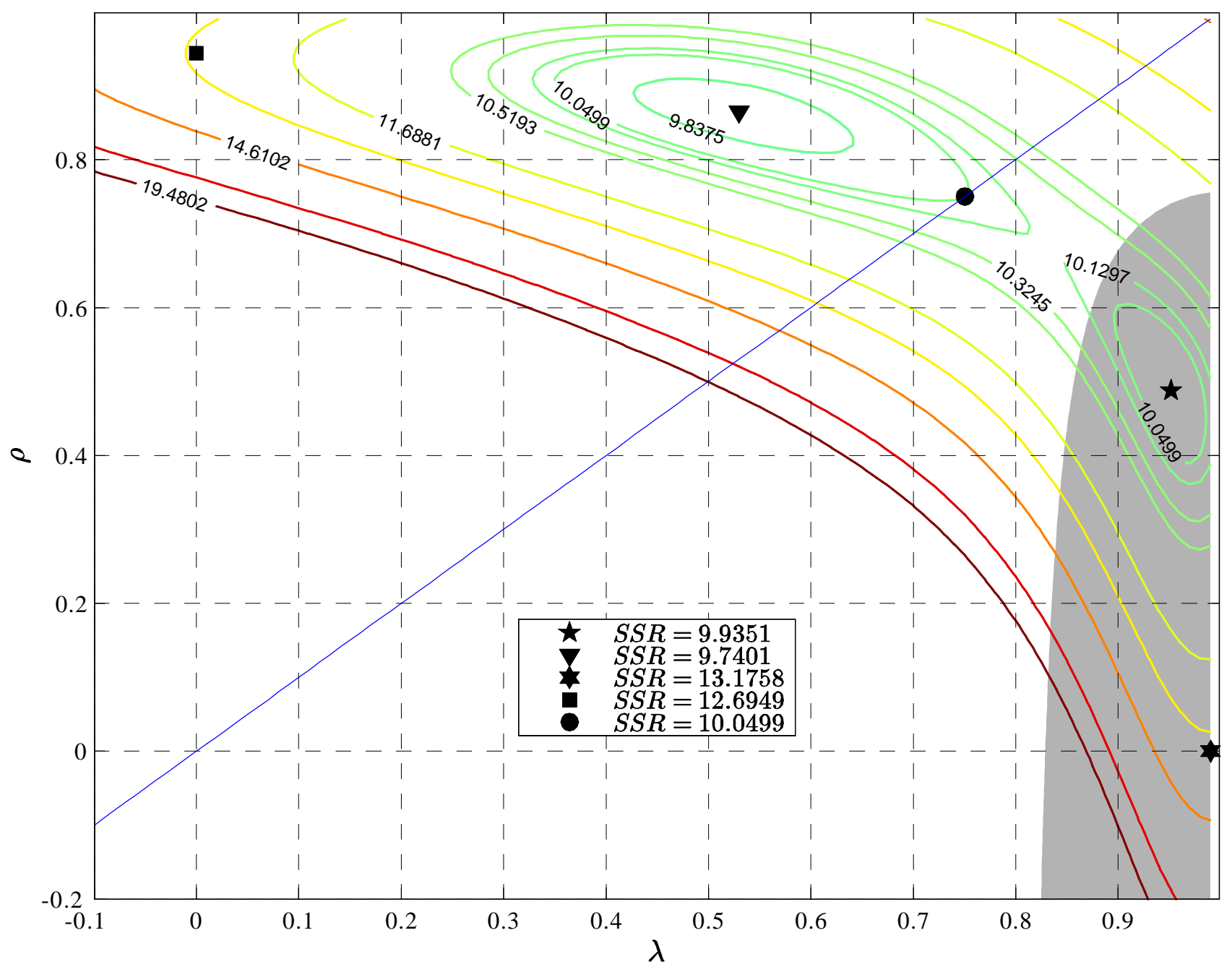

Figure 1: Value of $S S R$ as a function of $(\lambda, \rho)$. Notice that the total sum of squared deviations $T \operatorname{var}\left(i_{t}\right)=492.574$, where $T$ is the sample size. 